\title{
RELATO DE EXPERIÊNCIA: ATUAÇÃO DA RESIDÊNCIA PEDAGÓGICA EM UM INSTITUTO FEDERAL
}

EXPERIENCE REPORT: PERFORMANCE OF THE PEDAGOGICAL RESIDENCE IN A FEDERAL INSTITUTE

INFORME DE EXPERIENCIA: DESEMPEÑO DE LA RESIDENCIA PEDAGÓGICA EN UN INSTITUTO FEDERAL

\section{João Marcos Costa da Silva ${ }^{* 1}$, Érica Cupertino Gomes ${ }^{1}$}

${ }^{1}$ Laboratório de Ensino de Física, Licenciatura em Física, Universidade Federal do Tocantins, Araguaína, Brasil.

*Correspondência: e-mail: joaomarcoscosta7@gmail.com.

\section{Artigo recebido em 03/04/2020 aprovado em 09/04/2020 publicado em 17/04/2020.}

\section{INTRODUÇÃO}

Há muito se fala sobre a necessidade do aperfeiçoamento na formação de professores em detrimento às transformações sociais-culturais e suas pluralidades. Com isso, novos recursos e novas reelaborações, no âmbito educacional, são requeridas para atender as necessidades.

Nessa perspectiva, o programa Residência Pedagógica (RP) se apresenta como uma ferramenta de aperfeiçoamento na formação inicial de professores, no âmbito prático e teórico. Assim,

\begin{abstract}
a RP é parte da formação inicial, é essencialmente uma aprendizagem situada que acompanha a graduação e ganha sentido de especialização profissional. A proximidade está na imersão do estudante, no processo de contato sistemático e temporário com práticas profissionais reais - no caso, com professores e gestores educacionais (formadores) que atuam nos contextos das escolas públicas. (UNIFESP, 2006, p.48)
\end{abstract}

Visa garantir aos profissionais egressos dos cursos de licenciatura uma imersão na Unidade Escolar (UE) para desenvolver, ou melhorar, habilidades e competências, permitindo o fortalecimento da prática docente nas escolas de ensino fundamental e médio.

Com uma proposta alternativa aos Estágios Supervisionados, que não integra o estudante de licenciatura com tempo suficiente para ambientação e atuação na escola, a RP dispõe de um vasto cronograma para sua realização. A imersão inclui estar a par de todo o funcionamento da UE, consolidando a ação de diagnóstico em aspecto estrutural, administrativo e pedagógico.

Assim, permite que o residente adquira experiência ao planejar e ministrar aulas, elaborar e aplicar projetos de intervenção e atividades, articulando teoria e prática. Nesse cenário, promove ao graduando de licenciatura uma experiência que contribui substancialmente para a prática como futuro professor.

\section{METODOLOGIA}

Este é um trabalho de relato de experiência sobre a implementação da RP, subprojeto de Física, no Instituto Federal do Tocantins - Campus de Araguaína -, no âmbito da Universidade Federal do Tocantins.

O programa RP foi divido em etapas de implementação, distribuídas em:

I. Formação de Preceptores e Residentes;

II. Ambientação do Residente na escola campo;

III. Imersão do Residente na escolacampo;

IV. Elaboração do relatório final do residente. 
O programa teve período de vigência de 18 meses, de agosto de 2018 a janeiro de 2020.

\section{RESULTADOS E DISCUSSÃO}

O projeto RP Física, teve início em agosto de 2018 com a implementação da primeira etapa, Formação de Preceptores e Residentes, realizado em Agosto e em Setembro. Essa etapa teve por objetivo preparar os preceptores e os residentes para o novo programa. Tendo em vista a articulação da RP com a BNCC (Base Nacional Comum Curricular e Parâmetros Curriculares Nacionais) houve estudos e discussões junto aos núcleos de Biologia e Química a fim de promover um intercâmbio na área de Ciências Naturais.

Esse momento foi de suma importância para a compreensão da problemática que o residente ao se formar terá que enfrentar em sala de aula, grade curricular extensa e pouco tempo disponível para aplicação dos conteúdos.

Assim, de todas os argumentos apresentados dos preceptores e residentes, pudemos filtrar o que poderia ser mais conveniente de se aplicar em sala de aula ou não. Como, por exemplo, mesclar entre conteúdo apresentado em sala de aula e estudos dirigidos para conseguir abarcar todo o conteúdo programático.

Os assuntos apresentados e os questionamentos/levantamentos foram de extrema importância para refletir sobre ser professor, os desafios que terão que ser vencidos em sala de aula e a importância da conduta profissional em cada situação.

Por fim, nessa etapa, foi elaborado o plano de trabalho do residente, juntamente com o preceptor, para a execução das atividades na escola campo.

A segunda fase da RP teve execução de outubro de 2018 a janeiro de 2019, tendo como foco a ambientação do residente na UE. Foi realizado um levantamento crítico da escola campo, nesse caso o DOI: http://dx.doi.org/10.20873/uftsupl2020-8794
IFTO, nos colocando a par da estrutura física, administrativa e pedagógica.

Logo, como primeira impressão, o IFTO apresenta uma divisão administrativa ativa, com coordenações dos cursos distribuídas de forma a facilitar o fluxo comunicativo com a Reitoria.

Pode-se perceber também a democratização na tomada de decisões, nas quais todos os servidores possuem espaço de fala para opinar aspectos que podem ser modificados, fortalecendo a cooperação entre os diferentes núcleos dentro da instituição e maximizando a resolução de problemas.

O IFTO conta com um laboratório de Física que, apesar de um espaço pequeno, possui experimentos dos eixos gerais de Física Mecânica, Ondas e Termodinâmica e Eletricidade e Magnetismo, contando também com laboratórios de Informática. Quando se trata de Física, é crucial que as aulas teóricas tenham suporte de aulas experimentais, pois na prática os alunos conseguem compreenderlassimilar de forma mais eficaz o conteúdo que lhes é apresentado.

Também houve estudos associados aos documentos da organização da instituição, editais para monitorias, processos seletivos, regimento institucional, PPC's (Biotecnologia, Operador de PC's e demais cursos) e regulamentação da organização didático-pedagógico.

Ainda na segunda etapa, tive a oportunidade de participar de reuniões e eventos do IFTO, que contribuiu para o entendimento da dinâmica das atividades e de como são realizadas as tomadas de decisões do que será executado. Alinhando também, a dinâmica do professor em sala e aula e a interação/envolvimento dos alunos nessas atividades.

$\mathrm{Na}$ terceira etapa, imergimos como professores regentes em sala de aula, nas turmas do Ensino Médio (EM), incluindo o planejamento e 
gestão de aulas teóricas e experimentais, atividades e projeto de intervenção.

Durante o planejamento das aulas, uma das maiores preocupações que se tem é sobre a linguagem que deve ser utilizada para apresentação do conteúdo. $\mathrm{Na}$ universidade, estamos habituados a jargões técnicos e específicos de determinadas áreas da Física, um dos pontos mais difíceis de superar é saber transpor de forma didática, de forma que os alunos possam compreender.

Outro fator que influencia no planejamento é o tempo disponível para apresentar o conteúdo. Com duas aulas semanais de $50 \mathrm{~min}$ e um conteúdo programático extenso, saber o que é mais necessário, dentre os conceitos e formulações foi uma tarefa árdua.

Ainda nesse contexto, era importante alinhar o conteúdo em sala de aula com os experimentos disponíveis no laboratório para as aulas práticas. Assim, os alunos poderiam compreender de forma mais significativa cada fenômeno físico observado, levando em consideração a teoria que fora visto.

Também era importante estar em articulação com a competência 3 da BNCC (BRASIL,2018), que trata da análise de situações-problemas e aplicações do conhecimento científico e tecnológico. Assim, trazer um conteúdo técnico para a realidade do aluno foi um desafio, já que alguns conteúdos não são tão simples para exemplificar de forma prática.

O projeto de intervenção foi aplicado na turma da $2^{\circ}$ série do EM de Biotecnologia utilizando a ideia de jogos lúdicos. O jogo era um tabuleiro e havia perguntas referentes aos conteúdos vistos naquele ano, que envolvia calorimetria, termodinâmica, ondas, acústica e óptica. Os alunos interagiam e a colaboração entre eles aumentou, na medida em que discutiam os conteúdos de Física.

Por fim, a quarta etapa consistiu na elaboração do relatório final da RP, onde foi relatado todas as atividades desenvolvidas no programa, tanto as que foram realizadas na Universidade quanto as que foram na Unidade Escolar.

\section{CONCLUSÃO}

A RP se apresentou como uma ferramenta eficaz no que tange a experiência do graduando de licenciatura dentro de uma UE. Proporcionou uma interação maior com a dinâmica de sala de aula e com os demais aspectos da educação. Garantiu um maior preparo, tanto no âmbito teórico quanto prático, para a realidade da sala de aula como professor da rede básica de ensino, colocando metodologias em prática e adaptando as mesmas quando necessário, visando sempre um ensino de qualidade.

\section{AGRADECIMENTO}

Agradeço a CAPES, a Universidade Federal do Tocantins e ao Instituto Federal do Tocantins. Agradeço também a Profa. Dra. Érica Cupertino Gomes, ao Prof. Dr. Matheus Pereira Lobo e ao Prof. Mrs. Jonierson de Araújo da Cruz.

\section{REFERÊNCIAS}

UNIFESP. Plano pedagógico do curso de pedagogia. São Paulo, 2006/2010. Disponível em: <unifesp.br/campus/gua/home/index.php/cursos-degraduacao/2011-06-02-12-58-10>. Acesso em: 25 mar. 2020.

BRASIL. Base Nacional Comum Curricular: Ensino Médio. Brasília: MEC/Secretaria de Educação Básica, 2018. 